\title{
M-services Adoption in Oman Using Technology Acceptance Modeling Approach
}

\author{
Syed Jafar Naqvi \\ Sultan Qaboos University, Al-Khod, Sultanate of Oman
}

\begin{abstract}
M-services (Mobile services) and commerce are growing rapidly with the explosive growth of mobile devices, technologies and networks. Hence, many enterprises use them to grow revenue, reduce costs, maintain their competitive edge and achieve high performance. This advancement in mobile technologies has also influenced many government organizations to go mobile with their services and Oman is not an exception. Oman has just started to utilize mobile channels to offer Mservices to its citizens and clients. Although there were many services introduced, but it was hard to find evidence of any study conducted to determine their successes or failures. This study is an attempt to explore adoption issues of these services. This study used a survey questionnaire to collect data on users accessing the M-services, users' attitudes and the users' preferences to use these services. The results indicated that little over $50 \%$ of the users had positive attitudes towards the M-services and similar number of users indicated their preference to use them. This finding is in accordance to the Technology Acceptance Model (TAM), which states that the attitudes determine the intention to use which lead to the actual usage of the system. There were many users having negative attitudes toward these services. This study also explored some possible reasons which might be contributing towards the users' negative attitudes are the lack of users' awareness of these services; their usefulness; mobile technology literacy, publicity and marketing, which are needed to be addressed by the service providers for a greater success of the M-service adoption in Oman.
\end{abstract}

Keywords: M-services, Mobile technology, TAM, Oman and SMSs.

\section{Introduction}

In our traditional computing environment, it was necessary for users to reach his/her computer for any need of computing. This environment has made it hard for people, especially those on the move, like sales personals, police officers, students, utility workers and citizens interacting with public organizations. To reduce hardship, laptops were invented and later smaller and smaller computers, such as the PDAs, cell phones and other mobile devices were introduced with high processing power, storage, which were light enough to carry easily around with wireless communication capabilities.
Many experts argue that the future computer technology rests on mobile or wireless computing. As the number of mobile phones users is increasing worldwide, different organizations are offering their services using these mobile devices (Adagunodo, Alwodele \& Idowu, 2009).

These mobile devices in a wireless environment referred to as wireless mobile computing enables a real-time connection between a mobile device and other computing environments, such as the internet or an intranet (Turban \& Volonino, 2010).

Copyright (C) 2012 Syed Jafar Naqvi. This is an open access article distributed under the Creative Commons Attribution License unported 3.0, which permits unrestricted use, distribution, and reproduction in any medium, provided that original work is properly cited. Contact author: Syed Jafar Naqvi E-mail: cce3249@squ.edu.om 
Mobile technology with the introduction of internet enabled mobile phones, PDA's, Wi-Fi and wireless networks have allowed their users to enjoy all the benefits of telephones, information accessing, and text messaging such as SMS (Naqvi, Al-Shihi \& Ali, 2011). At the end of 2001, approximately $14 \%$ of the world population - (850 Million people) were mobile phone users. This growth has been spectacular especially in Europe after the telecom industry de-regulation and adoption of Global System for Mobile (GSM) communications (Sadeh, 2002). Now, mobile phones are no longer used only for voice communication but are a convenient way of connecting to the Internet and are used for transferring data, mailing, and doing small scale business transactions (Sadeh, 2002). Mobile phone penetration is well above the home PCs usage in Europe and it seems that the trend will continue (Varshney, 2000). The internet access via mobiles or wireless devices in Middle East has risen from 33.5\% in 2007 to $40 \%$ in 2009. Furthermore, the percentage of desktops use decreased from $63.50 \%$ to $58.93 \%$ as laptop usage increased from $81.35 \%$ to $82.80 \%$ (Mobile Net Users on Rise in Middle East, 2009). Mobile or wireless devices are widely used not only by developed countries but also commonly used by many other developing nations of the world including Oman.

Mobile devices are now becoming a part of our daily and business lives. Mobile devices have changed how people interact and conduct business, driving demand for the next generation of products and services (ESCWA, 2007). With an estimated one trillion networked devices coming into play over the next five years, enterprises are increasingly looking for advances in wireless technology and mobile devices to grow revenues, reduce costs, maintain their competitive edge and achieve high performance (AMOS 2010).

Everyone is amazed at the quick proliferation of mobile phones in the developing world (Wayan, 2010). Just beginning a few years ago, started expanding even in impoverished areas with no other precedent for technology adoption, mobile phone usage has exploded beyond the predictions of most experts in the field (Ngugi, Pelowski, \& Ogembo, 2010). A recent estimate indicated that over half of the Omani population has mobile devices, while the mobile infrastructure in Oman is currently covering $95 \%$ of the country (Ministry of National Economy 2007).

\section{Background to the Study}

The Sultanate of Oman is one of the Gulf Cooperation Council (GCC) country located on the south east of the Arabian Peninsula. According to the latest estimates (Ministry of National Economy - Oman 2007), in 2006 Oman had a population of 2.677 million people. However, nearly 693,000 residents, (25.9 per cent of the population), were expatriates. Oman's currency is the Rial which is about USA $\$ 2.60$ per unit OMR (Omani Rial). The country's main revenue comes from oil and natural gas. The country's economic status was substantially enhanced by rising oil prices (Ministry of InformationOman, 2008a, 2008b). According to the Ministry of National Economy-Oman (April 2008), Oman's 2008 GDP reached about OMR 13,737 million, compared to OMR 104 million in 1970. Oman enjoys a stable political, economical and social system under the leadership of Sultan Qaboos and achieved a remarkable progress in both economical and social fields (Al-Gharbi \& Ashrafi, 2010).

According to the United Nation 2008 EGovernment readiness report, Oman has jumped up 28 points in this ranking position from $112^{\text {th }}$ position in 2005 to $84^{\text {th }}$ position in 2008. Oman ranks $60^{\text {th }}$ position in the eParticipation out of 192 countries. The number of Internet subscribers and mobile subscribers are rising dramatically over the past few years (Naqvi and Al-Shihi, 2009). This rise is a clear indication of the progress made. The pace of progress through initiatives to build of ICT infrastructure, over electronic services and build capacity within the country to harness the power of 
technology (Information Technology Authority, 2009).

Oman has just started to utilize mobile channels to offer M-services to its citizens and clients. Some of the examples are: Muscat Municipality which developed an SMS-Parking Service system which enables motorists to pay parking fees via SMS; Higher secondary school students can now retrieve their end of semester grades (via SMS) by messaging their student seat numbers to a phone number designated by the Ministry of Education. Similarly, many other organizations are offering M-services through SMS, messaging to clients to inform them about their different activities. There are many other applications of M-services in Oman, which are needed to be explored further and to see their influence on their users.

Purpose of the Study: This study is an attempt to overview the M-services initiatives taken in Oman and identifying the factors, which are inhibiting their swift adoption among users in spite of their numerous advantages, using the Technology Acceptance Model (TAM) as developed by Fred Davis (Davis \& Arbor, 1989).

\section{Literature Review}

\section{Overview of M-services}

M-services have two major characteristics that differentiate it from other forms of services, which are mobility and broad reach (Turban \& Volonino, 2010). M-services are based on the fact that users carry mobile devices any where they go and users can be reached at any time. We get additional attributes such as ubiquity, convenience, instant connectivity, personalization, localization of products and services. Mobile devices create an opportunity to deliver new services to existing customers and to attract new ones. Oman has capitalized these opportunities and started offering many $\mathrm{M}$ services.

\section{M-services in Oman}

This section outlines the major M-services offered in Oman categorized in two groups; Push and Pull services. Push services are passive in nature where clients or end-users usually receive notifications about certain activities or events. On the contrary, Pull services ask users to play a more active role in either initiating the service or responding to queries via SMS using mobile devices.

\section{Pull Services}

The Royal Oman Police (ROP) initiated an M-service allowing drivers to inquire and receive information about their traffic offences. Motorists are required to send a message of their IDs and vehicle details to '3004' and they will receive information on the number of traffic offences and amount payable. ROP plans to enable the system to notify drivers of their offences as soon as they happen, which will be useful to parents and business owners to know the traffic offences committed by their sons/daughters and drivers driving company's official cars.

The Ministry of Education now sends the final general certificate results to students via SMSs. Alternatively, students can inquire about their results by messaging their seat numbers to '92020' and receive their final marks (Oman Mobile, 2007a). In addition, the Higher Education Admission Center now informs students of their admission status in different institutions via SMSs allowing them to accept or reject the offer by messaging back their choices.

Muscat Municipality and Oman Mobile have introduced a new service for paying the parking fee in MBD (Muscat Business District) and its surrounding areas. The service is simple to use, the user should have a mobile phone with either a pre or post paid option and the fee will be deducted instantly or sent through a monthly mobile phone bill. The user can park the car and send an SMS to "90091" with the details of the car plate 
number and the minutes for which the parking is needed. The users will get a confirmation message for a successful transaction. The user will then get a reminder message five minutes before the allocated time expires either to move the vehicle or renew his/her parking time (Oman Mobile 2010). This flow of information from the user goes to the Oman mobile and passes to the Muscat Municipality data bank. The inspector receives the information on his PDA and uses it while inspecting the parking sites for violations.

\section{Push Services}

Muscat Securities Market has developed a paid service that enables investors to receive regular updates on market and stock alerts via SMS (Oman Mobile, 2007b). The service also enables users to get a SMS every 30 minutes on market movers - top winners, losers and most active companies (Oman Mobile, 2007c).

The Civil Aviation and Meteorology in cooperation with Oman Mobile has introduced a weather forecast service for most towns in Oman that allows users to receive weather reports on their mobiles (Oman Mobile, 2007d).

Banks and M-services Most banks in Oman are now offering M-services where the clients can receive updates on their bank accounts activities for amount coming in or going out of their accounts.
Commercial Ads and Clients Most shopping Malls and outlets are now sending their ads and promotional incentives to the local clients via SMSs.

Other organizations have also started to send bulk messages to citizens informing them about their activities and events. For example, the Public Authority for Social Insurance has currently begun a public campaign to publicize its services and their perceived benefits to clients. One of the means used was to send advertising SMS to all residents in Oman.

Another example is in Oman Tender Board and Ministry of Manpower where they now send notification messages via SMSs to clients about their transactions and/or other different issues such as new tenders and job vacancies etc.

As we will be exploring the users acceptance of these M-services in the light of Technology Acceptance Model which is briefly described in the following section.

\section{Technology Acceptance Model}

The Technology Acceptance Model (TAM) was introduced and developed by Fred Davis in 1986 (Norazeh \& Ramayah, 2010). TAM is a model derived from a theory that addresses the issue of how users come to accept and use specific technology (see Fig. 1). 


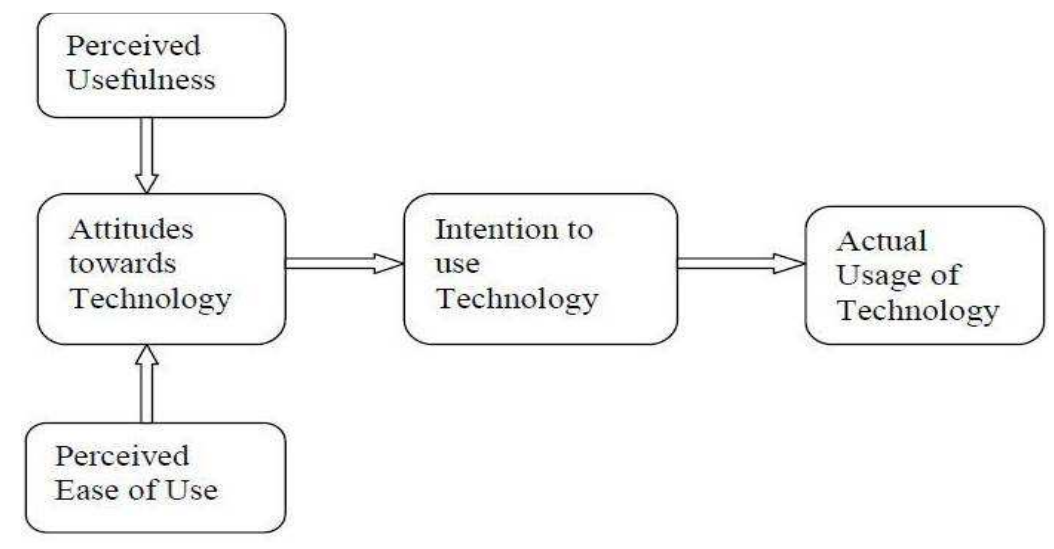

Fig 1. Technology Acceptance Model (TAM)

The model suggests that when users are offered or presented a new system or software package a number of variables influence their decisions about how and when they will use it, specifically perceived and usefulness variables (Davis \& Arbor, 1989). TAM is designed to apply only to computer usage behavior, but it can be readily extended to apply to any type of technology, and consequently it could be applied to the study of users' acceptance of eGovernment (Norazah and Ramayah, 2010).

Perceived usefulness and Perceived ease of use are the two major determinants of users' attitudes. This leads to users' intention to actual systems usage. This model is used in our study to examine the users' attitudes and their adoption of M-services.

\section{Research Methodology}

An initial study on the M-services adoption in Oman was conducted with a sample size of 77 users of which $61 \%$ were male and $39 \%$ female. The data was collected in year 2011 from the users of Pull services to investigate their acceptance as these services are initiated by users.

A questionnaire survey instrument was used to collect data from M-services users, which consists of three major domains related to: accessing M-services, users' attitudes toward the service and their preferences M-services over the Traditional system. Responses to each question were based on a scale of 1 to 5 , where 1 = Strongly Disagree, 2 = Disagree, 3 = Uncertain, 4 = Agree, $5=$ Strongly Agree. The questionnaire was administered in the same way to all M-services users. Only the questionnaires which were responded and filled up completely were taken into consideration. A simple analysis was conducted through computing and comparing the percentages of the users' responses.

\section{Data Analysis and Discussions}

\section{Accessing M-services}

The feedback on accessing the Pull Mobile services by users indicated that $70 \%$ of the total 77 users responded in agreement that M-services are accessible at any time of the day with moderate comfort as 59\% agreed on its comfortable access. However $47 \%$ of the users feel that these services are not accessible from all locations as shown in Figure 2. As we know the M-services depend on the network availability, signal strength and moreover they have regional scope. Hence the reasons for not accessing the Mservices could be either technical or the users' inability to correctly following the procedure to initiate the services. 


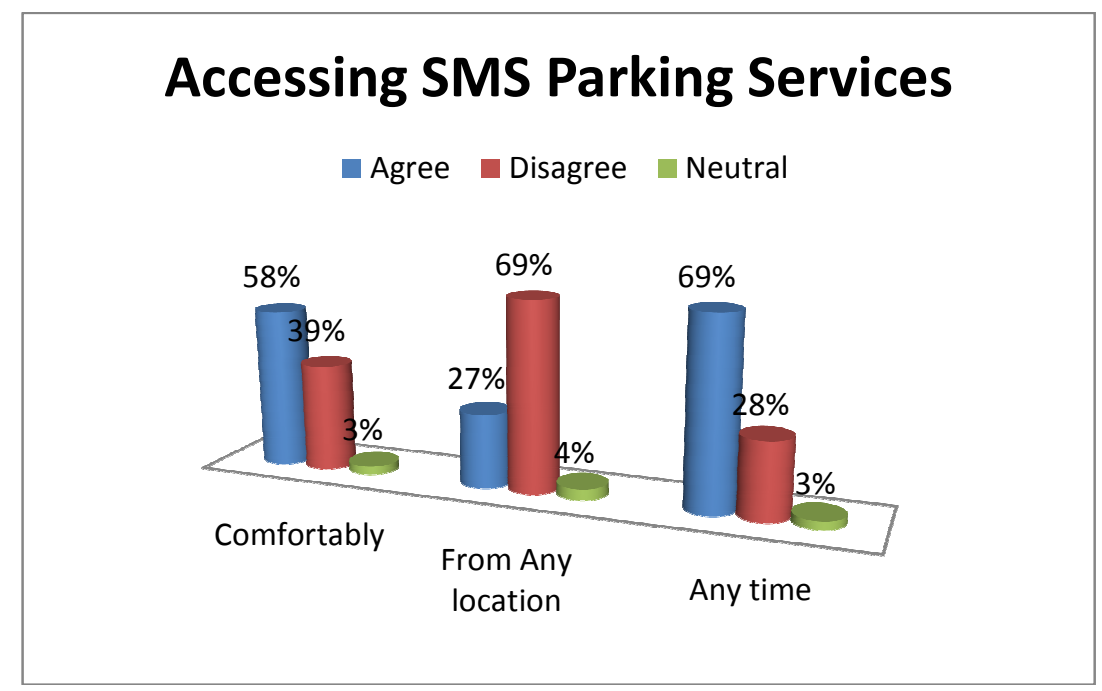

Fig 2. Accessing M-Service/s

\section{Attitudes Towards M-Service}

On the questions related to attitudes specially the M-services usefulness, a good number of respondents i.e. $66 \%$ of them agree that M-services are useful as shown in Figure 3 . But only $53 \%$ of the respondents feel that M-services are easy to use. The similar responses on attitudes could be seen as many users (51\%) feel that M-services are friendly and (61\%) users feel at ease while using these services. The results indicate that a little over $50 \%$ of the mobile users have positive attitudes toward the M-services. Hence many of the users will not prefer to adopt these services. According to TAM the users' attitudes lead to users' intention to actual system usage. Moreover, $57 \%$ of the users feel that the services are not fast enough, which could be another inhibiting factor for the quick adoption of the Mservices. 


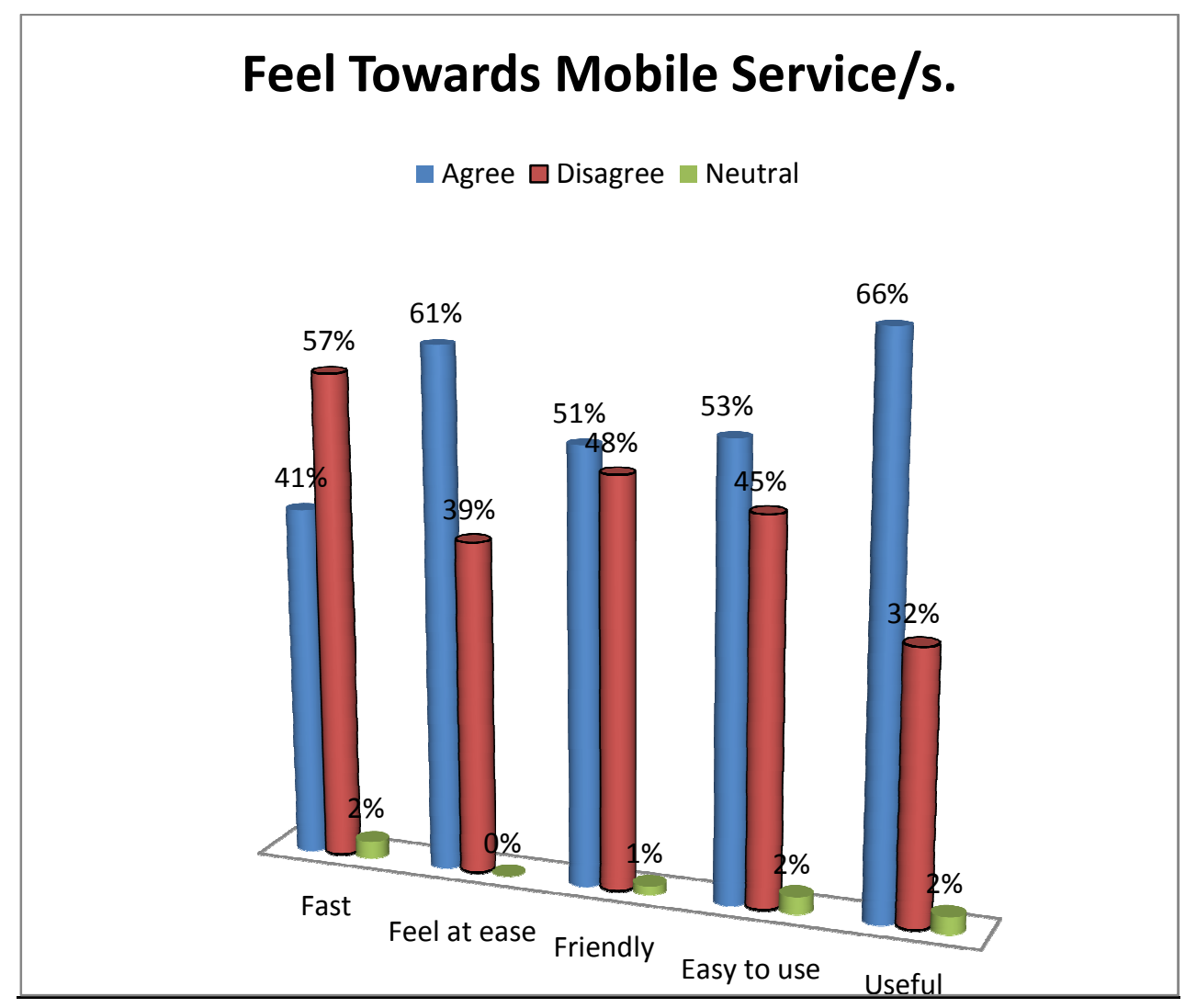

Fig 3. Feel towards M-Services

\section{M-services and Users' Preferences}

Referring to figure 3 and 4, a little over $50 \%$ of the users have shown a positive attitude toward the M-services and similar number of users (58\%) agree and prefer M-services over the traditional systems which are in line with TAM, where attitudes determine the intention and actual usage of the system see Figure 1.
Having said this, a large number of users (nearly 40\%) indicted their rejection, to these M-services and still prefer to continue using the traditional ways.

This may not be called a great success and may be referred to as a slow adoption of these services, which probes to further investigations. 


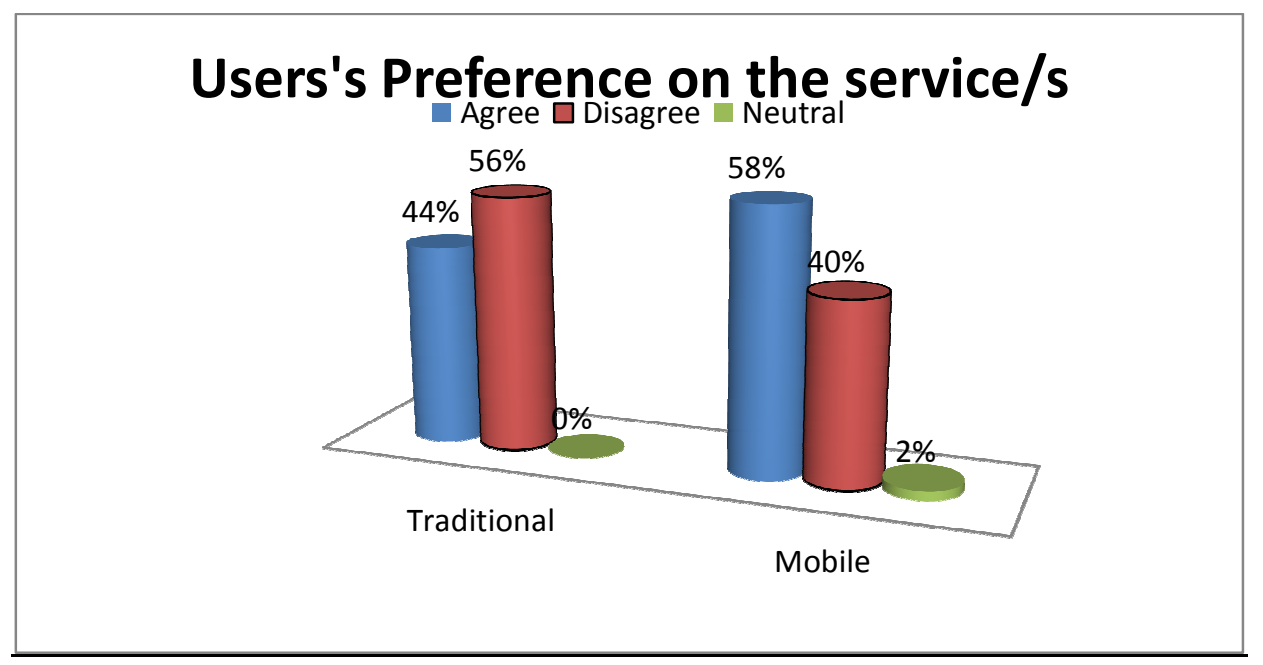

Fig 4. Preference towards Services

\section{Possible Reasons for Slow Adoption of the M-Services}

Exploring more on these issues and understanding the possible reasons for a slow adoption of these services, informal interviews were conducted with the users and the following observations were made.

- Many mobile users were unaware of these M-services initiatives as there were no or very little publicity and marketing campaigns to promote them.

- Many individuals were unaware of the benefits of using M-service. Hence they were reluctant to change from the traditional ways of doing things to the newly offered services.

- Many users were not fully comfortable in using their mobile devices and were not so keen to try the new services.

- Many users experienced sometimes slow responses from the mobile networks or its unavailability. Such incidents may contribute negatively towards users' attitudes, trust, satisfaction, and the services credibility.
- Many users felt the costs of SMS and MMS were high which limit the adopters of these services.

\section{Summary and Conclusion}

The results of this study showed that a little more than half of the users were able to access these M-services comfortably and had positive attitudes. They felt the services were useful, easy to use and friendly and indicated their preference to choose them over the traditionally offered services. This finding is in line with the Technology Acceptance Model, which states that the attitudes determine the intention to use which lead the users to the actual usage of the system.

Still a large number of respondents were either uncertain or disagree with the services and had negative attitudes towards them. There could be many possible reasons contributing to their negative attitudes. The most important ones are the lack of users' awareness of these services, their usefulness; mobile technology literacy, a solid publicity and marketing campaigns.

The service providers may play a major role in exploring the needs of the users before developing the services for them. The 
services needed to be more user friendly and offered using fast and reliable mobile networks. The service providers must introduce their new services with aggressive publicity and marketing campaigns, if they want to see swift adoption of M-services offered in Oman.

Since there is always room for improvement to offer better services to clients, the service providers need to explore further opportunities. The main limitations of the study are the sample size and robust analytical model. There is a need for further exploration to see the impact of each individual M-service offered to its users. The outcome of this research work may provide a background for further investigations and also other potential M-Services opportunities offered in the Sultanate of Oman or elsewhere.

\section{References}

Adagunodo, E. R., Awodele, O. \& Idowu, S. (2009). "SMS User Interface Result Checking System," Issues in Informing Science and Information Technology, $\operatorname{Vol}(6), 101-112$.

Al-Gharbi, K \& Ashrafi, R. (2010). "Factors Contributing to Slow Internet Adoption in Omani Private Sector Organizations," Communication of the IBIMA, Vol. 2010.

AMOS, (2010). “Accenture Mobility Operated Services: Mobility for Better Business Outcomes,",[ [Online], [ Retrieved August 8, 2010],

http://www.accenture.com/Global/Services /By_Industry/Communications/Services/Acc entureMobilityOperatedServices.htm

Davis, F. D. \& Arbor, A. (1989). "Perceived Usefulness, Perceived Ease of Use and User Acceptance Of Information Technology," MIS Quarterly, Vol. 13(3), 319-340.

ESCWA. (2007). "National Profile of the Information Society in the Sultanate of Oman," United Nations, New York.
Information Technology Authority (2009). "About ITA," [Online], [Retrieved Jan 7, 2010], http://www.ita.gov.om

Ministry of Information - Oman (2008a). "His Majesty Sultan Qaboos bin Said," [Online],[Retrieved December 13, 2008], http://www.omanet.om/english/history/sul tan.asp?cat=hist

Ministry of Information - Oman (2008b). "Useful information," [Online], [Retrieved December 13, 2008], http://www.omanet.om/english/useful/basi c.asp?cat=use

Ministry of National Economy - Oman. (2007). Statistical Year Book, Vol. 35.

Ministry of National Economy - Oman. (2008). 'Monthly statistical bulletin,' Vol. $19(4)$.

Mobile Net Users on Rise in Middle East (2009). "The Ultimate Middle East Business Resource," [Online], [Retrieved July 28, 2011],

http://www.ameinfo.com/187272.html

Naqvi, S. H. \& Al-Shihi, H. (2009). "MGovernment Services Initiatives in Oman," Issues in Informing Science and Information Technology, Vol. (6), 817-824.

Naqvi, S. J., Al-Shihi, H. \& Ali, S. (2011). "Mobile Services in Oman: A Feedback on SMS-Parking Service," Proceedings of Informing Science \& IT Education (InSITE2011), 18-23 June 2011, Novi Sad, Serbia.

Ngugi, B., Pelowski, M. \& Ogembo, J. G. (2010). "M-PESA: A Case Study of the Critical Early Adopters' Role in the Rapid Adoption of Mobile Money Banking in Kenya," [Online], Retrieved Nov15, 2010], http://www.ejisdc.org

Norazah, M. Suki \& Ramayah, T. (2010). "User Acceptance of the E-Government Services in Malaysia: Structural Equation Modeling Approach," Interdisciplinary Journal 
of Information, Knowledge, and Management, Vol 5.

Oman Mobile. (2007a,b,c,d). "Products and Services," [Online], [Retrieved May 5, 2008], http://www.omantel.net.om

Oman Mobile. (2010). 'Products and Services,' [Online], [Retrieved August 8, 2010],

http://www.omantel.net.om/OmanWebLib/I ndividual/Promotions/topup_promotion.asp $\mathrm{x}$ ?linkId $=3$

Sadeh, N. (2002). M-Commerce: Technologies, Services, and Business Models, John Wiley Publishing, Hershey, PA.

Turban, E., Volonino, L., Ephraim McLean \& James Wetherbe (2010). Information Technology for Management-Transforming Organizations in the Digital Economy, John Wiley Publishers, USA.

Varshney, U. \& Vetter, R. (2000). "Emerging Mobile and Wireless Networks (Technology Information)," Communications of the ACM, Vol. 43(6), 73-81.

Wayan, Vota. (2010). "A New ICT4D Paradigm: Women + Mobile Phones + mServices = Economic Development, Technology salon," Washington D.C., [Online],[Retrieved August 8, 2010], http://www.technologysalon.org 